\title{
Stair-like Multivariable Generalized Predictive Control of Pulverizing System in Thermal Power Plants
}

\author{
ZHANG Jiansheng ${ }^{1}$ \\ Electricity Production Department \\ Shenhua Guoneng Energy Group Corporation, Limited \\ Beijing, China \\ zjs3241@163.com
}

ZHANG Gang ${ }^{2}$

School of Control and Computer Engineering

North China Electric Power University

Beijing, China

1562820108@qq.com

\author{
Gao Yaokui ${ }^{3}$ \\ School of Control and Computer Engineering \\ North China Electric Power University \\ Beijing, China \\ Gaoyaokui05@126.com \\ $\mathrm{Hu}^{\text {Yong }^{4}}$ \\ School of Control and Computer Engineering \\ North China Electric Power University \\ Beijing, China \\ ncepu_hu@yahoo.com
}

\begin{abstract}
Pulverizing system is an important part in the clean and efficient utilization of coal in thermal power plant, the optimal control of the system is an important way to achieve this goal. This paper presents a stair-like multivariable generalized predictive control scheme for a pulverizing system. This scheme focuses on the problem of predictive control algorithm in practical application, especially when it incorporates feedforward control ideas. Simulation results showed that the scheme are able to realize the decoupling control of the pulverizing system, avoid the problem of matrix inversion, reduce the amount of calculation, and has certain engineering application value.
\end{abstract}

Keywords-Power Plants; Pulverizing System; Predictive Control;

\section{INTRODUCTION}

"Rich in coal but poor in oil and gas" is a distinctive feature of China's present energy structure. The National Potential Assessment of Coal Resources shows that China's total coal resources are 5.9 trillion tons, which accounts for $94 \%$ of the total primary energy resources; however, the oil and natural gas resources account for only $6 \%$. The total energy consumption in 2016 is about 4.36 billion tons of standard coal, of which, 2.7 billion tons of coal were consumed, which accounts for $62 \%$ of the total energy consumption; in which, the coal consumed for power generation accounts for $53 \%{ }^{[1,2]}$. Further, Coal-fired power generation capacity accounted for more than $60 \%$ of the total installed power generation capacity in China (about 14 billion kilowatts). Therefore, the clean and efficient use of coal in China is crucial, especially in coal-fired power plants, which will be of great significance in alleviating the pressure on China's resources and the environment, and will ensure the sustainable development of the China's energy system.

This paper is supported by National Natural Science Foundation of China (51776065); Control Technology on Operating Flexibility of the Thermal Power Unit Based on its Energy Management (2017)
In coal-fired power plants, the clean and efficient use of coal is affected by many factors, such as coal quality, type and dryness, distribution of primary and secondary air, burner structure, operating conditions of units, etc. These factors involve the pulverizing, air distribution, desulfurization, denitration, dust removal, and coordination system, which make it difficult to analyze them integrally. In this paper, we mainly study the optimization control of pulverizing system to improve the stability and economy of boiler combustion, thereby achieving the clean and efficient use of coal in coalfired power plants.

The pulverizing system is a typical three-input, threeoutput, nonlinear, and time-varying system, and there is a serious coupling between each variable. The traditional control system generally consists of three independent single-loop, that is, the mill outlet temperature is controlled by the cold air valve, the primary air flow is controlled by the hot air valve, and the output of the pulverizing system is controlled by the coal feeder, this control method fails to achieve decoupling control of pulverizing system; the output of pulverizing system is generally controlled by the coal feeder indirectly, and its control accuracy is very poor. In addition, the mill outlet temperature is the main factor affecting the degree of dryness and ignition heat of pulverized coal, which is affected by both the raw coal moisture content, the coal feed flow, the primary air flow and the primary air temperature. Among them, the raw coal moisture is an uncontrollable variable, the coal feed flow is controlled with the change of unit load, the primary air flow is controlled with the change of coal feed flow, none of the three can be used as control method for mill outlet temperature, thereby, the mill outlet temperature is essentially controlled by primary air temperature at the inlet of coal mill. The higher the primary air temperature at the inlet of the coal mill, the lower the pulverized coal moisture at the outlet of the coal mill, the 
lower the latent heat of vaporization and the ignition heat required for the combustion, which is more conducive to the safe, stable and economical operation of the boiler; however, the excessive primary air temperature at the inlet of coal mill may cause spontaneous combustion of pulverized coal or even an explosion accident, which seriously affect the safety of milling equipment. Therefore, it is of great importance to study the optimal control technology of pulverizing system to realize the safe, stable and economical operation of milling system, and improve the stability and economy of boiler combustion.

Recently, some advanced intelligent control algorithms has been applied to the design of pulverizing control system. Combined the PID algorithm and the predictive control algorithm, Sun $^{[3]}$ et al. proposes a PID-GPC predictive control algorithm, Based on this algorithm, a control scheme for the pulverizing system is designed. The simulation show that the algorithm has better robustness than general feedforward decoupling PID control and GPC control, however, this algorithm fails to consider some practical engineering problems and is not conducive to engineering applications. On the basis of a T-S fuzzy model of a pulverizing system, Zhang $^{[4]}$ et al. present a tracking control scheme for a pulverizing system, and some important performance indicators was considered to ensure the real-time performance of the control system, the simulation verified the effectiveness and real-time performance of the control system, However, this cannot achieve decoupling control of the pulverizing system. Considering the effect of coal moisture on the energy balance of the coal mill, Zeng ${ }^{[5]}$ et al. established a dynamic model of a coal mill and designed an optimized control scheme for the coal mill, the simulation results also show the accuracy of the model and the effectiveness of the control scheme, However, the control scheme is only for the coal mill, the control variable is the inlet primary air temperature and primary air flow, which are not direct control variables of pulverizing system. Through modeling and analysis, Gao ${ }^{[6]}$ et al. proposed an estimation signal for pulverized coal flow at the outlet of coal mill, and this signal was integrated into the design of an intelligent control scheme for the pulverizing system. Finally, a control scheme for the pulverizing system based on state space prediction control was designed, the simulation indicated that the output control precision of the pulverizing system was improved and the ability to resist disturbances was enhanced, however, the control scheme does not consider matrix inversion and tracking switching issues from an engineering perspective, Therefore, it is not conducive to engineering applications

In summary, the above research content are hard to apply to engineering practice, and only remain in the simulation stage. This article will directly address the engineering applications: 1) the multivariable generalized predictive control algorithm is adopted to realize the decoupling control of pulverizing system, thereby avoiding the coupling fluctuations of the controlled variables; 2) the stair-like solution idea is adopted to solve the control law of the predictive controller, thereby avoiding the inversion problem in the process of solving diophantine equation; and 3) The feedforward experience in traditional control schemes is integrated into the design of this control scheme.
This paper is organized as follows. Section 1 provides a brief introduction for pulverizing systems and simulation models. Section 2 deduces the stair-like multivariable generalized predictive control algorithm. Section 3 designs an optimized control scheme of the pulverizing system on the basis of the algorithm deduced in the former section. Section 4 simulates and verifies the proposed control scheme. Section 5 presents the conclusion of this paper.

\section{BRIEF INTRODUCTION FOR PULVERIZING SYSTEMS AND SIMULATION MODELS}

A typical positive-pressure, direct-fired, pulverizing system is mainly composed of a coal feeder, a coal mill, a primary fan, a sealed fan, a separator, and a burner (see Fig. 1). The raw coal is fed into the coal mill via a coal feeder, and then ground to pulverized coal; the primary air is boosted by a fan and divided into two parts, one part directly enters the cold air duct, while the other part is heated by an air preheater and then enters the hot air duct. These two parts of wind are mixed and then sent to the coal mill. The mixed primary air temperature and primary air flow are controlled by a cold air valve and a hot valve, these two valves cooperate to complete the drying and conveying tasks of the pulverized coal. In addition, the sealed fan is used to seal the coal mill to prevent the pulverized coal from leaking.

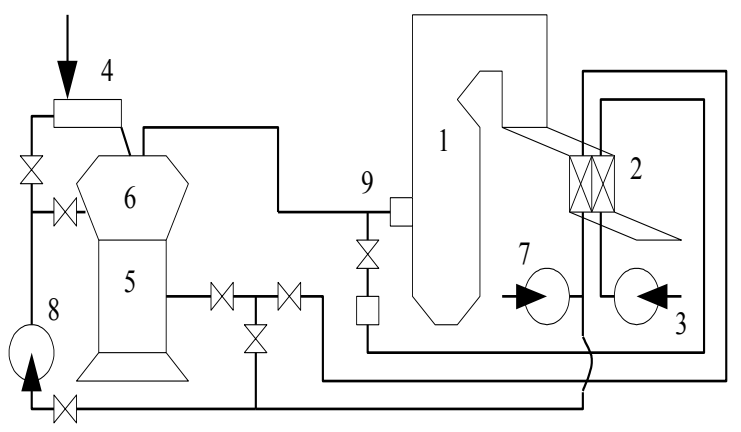

1.boiler furnace, 2.air preheater, 3.air blower, 4. coal feeder, 5. coal mill, 6. Separator, 7. primary fan, 8. sealing fan, 9. burner

Fig. 1 Schematic of a medium speed mill, positivepressure, direct-fired pulverizing system

The research work in this paper is based on a model of a MPS positive-pressure, direct-fired, pulverizing system established in [5]. This model which is established based on the mass balance and energy balance of a coal mill, the specific form of the model is as follows:

Where, $W_{\text {air }}$ is primary air flow, $\mathrm{kg} / \mathrm{s} ; \theta_{\text {in }}$ is primary air temperature, $\mathrm{kg} / \mathrm{s} ; M_{c}$ is raw coal content in coal mill, $\mathrm{kg} ; M_{p f}$ is coal powder content in coal mill, $\mathrm{kg} ; \theta_{\text {out }}$ is coal mill outlet temperature, ${ }^{\circ} \mathrm{C} ; u_{L}$ is valve opening of cold air, $\% ; u_{H}$ is valve opening of hot air, $\% ; W_{c}$ is coal feed flow, $\mathrm{kg} / \mathrm{s} ; M_{a r}$ is raw coal moisture, $\%$.

The input of the model are $u_{L}, u_{H}$, and $W_{c}$. The output of the model are $W_{\text {air }}, \theta_{\text {out }}$, and $W_{p f}$. The states of the model are $\theta_{\text {in }}, W_{\text {air }}, M_{c}, M_{p f}$, and $\theta_{\text {out }}$. The time-varying parameters is $M_{a r}$. 


$$
\left\{\begin{array}{l}
\dot{W_{\text {air }}}=-0.0971 W_{\text {air }}+0.183 u_{L}+0.551 u_{H}-22.2 \\
\dot{\theta_{\text {in }}}=-0.272 \theta_{\text {in }}-198+\frac{7.98 u_{L}+192.0 u_{H}}{\left(0.183 u_{L}+0.551 u_{H}\right)\left(8 \theta_{i n} \times 10^{-5}+0.995\right)} \\
\dot{M}_{c}=-0.452 M_{c}+W_{c} \\
\dot{M_{p f}}=0.452 M_{c}-\left(0.00285 \theta_{\text {in }}+0.778\right) W_{\text {air }}{ }^{2} M_{p f} \times 7.95 \times 10^{-4} \\
\dot{\theta_{\text {out }}}=\frac{1}{4171.7}\left(1.1 M_{c}+0.233 M_{p f}+9.42 W_{\text {air }}-2.414 W_{\text {air }} \theta_{\text {out }}+2.151 W_{\text {air }} \theta_{\text {in }}+\text { tempA }+ \text { tempB }\right)
\end{array},\right.
$$

$$
\begin{gathered}
\text { temp } A=\frac{2.17 u_{3}\left(1.88 \theta_{\text {out }}+2499\right)\left(M_{\text {ar }}-\frac{1.1 M_{\text {ar }}}{\theta_{\text {out }}{ }^{0.45}}\right)}{\left(\frac{1.1 M_{a r}}{\theta_{\text {out }}{ }^{0.45}}-100\right)}, \\
\text { tempB }=-2.17 \theta_{\text {out }} W_{c}\left(0.01 M_{\text {ar }}-1.0\right)\left(\frac{4.62 M_{\text {ar }}}{\theta_{\text {out }}{ }^{0.45}\left(\frac{1.1 M_{\text {ar }}}{\theta_{\text {out }}{ }^{0.45}}-100\right)}-1.09\right),
\end{gathered}
$$

\section{OPTIMAL CONTROL OF THE PULVERIZING SYSTEM}

In consideration that predictive control algorithms generally perform well in strong coupling multivariable systems without being decoupled ${ }^{[8-10]}$, such an algorithm is adopted as the core of the control system design in this paper, and a stair-like solution idea was adopted to avoid matrix inversion problems.

\section{A. Stair-like multivariable generalized predictive control algorithm}

Assume that the system is based on the following discretetime CARIMA model ${ }^{[8-10]}$ :

$$
\boldsymbol{A}\left(z^{-1}\right) \boldsymbol{y}(k)=\boldsymbol{B}\left(z^{-1}\right) \boldsymbol{u}(k-1)+\boldsymbol{\xi}(k) / \Delta
$$

Where $\boldsymbol{y}(k)$ is the system's m-dimensional output; $\boldsymbol{u}(k)$ is the system's p-dimensional input; $\xi(k)$ is the system's mdimensional noise vector; and:

$$
\begin{gathered}
\boldsymbol{A}\left(z^{-1}\right)=1+\boldsymbol{A}_{1} z^{-1}+\cdots+\boldsymbol{A}_{n_{a}} z^{-n_{a}}, \\
\boldsymbol{B}\left(z^{-1}\right)=\boldsymbol{B}_{0}+\boldsymbol{B}_{1} z^{-1}+\cdots+\boldsymbol{B}_{n_{b}} z^{-n_{b}},
\end{gathered}
$$

Where $\boldsymbol{A}_{i}$ is a $\mathrm{m} \times \mathrm{m}$ dimension matrix, and $\boldsymbol{B}_{i}$ is a $\mathrm{m} \times \mathrm{m}$ dimension matrix.

Assume that the objective function of the control system is as fellow:

$$
\begin{array}{r}
\boldsymbol{J}=\sum_{j=1}^{N}\left\|\widehat{\boldsymbol{y}}(k+j \mid k)-\boldsymbol{y}_{\boldsymbol{d}}(k+j)\right\|_{\boldsymbol{I}_{m}}^{2}+ \\
\sum_{j=1}^{N_{u}}\|\boldsymbol{\Delta} \boldsymbol{u}(k+j-1)\|_{\Lambda}^{2}
\end{array}
$$

Where $\hat{\boldsymbol{y}}(k+j \mid k)$ is a $\mathrm{j}$-step prediction for $y(k) ; \boldsymbol{\Lambda}$ is a positive semi-definite matrix, generally take $\boldsymbol{\Lambda}=$ $\operatorname{diag}\left(\lambda_{1}, \cdots, \lambda_{p}\right)$, and $\lambda_{i} \geq 0 ; \boldsymbol{y}_{d}(k+j)$ is the softening sequence vector of the set value, which generated by:

$\boldsymbol{y}_{d}(k)=\boldsymbol{y}(k)$

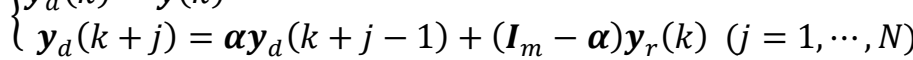

Where $\boldsymbol{\alpha}=\operatorname{diag}\left(\alpha_{1}, \cdots, \alpha_{m}\right)$, and $0 \leq \alpha_{i}<1 ; \boldsymbol{y}_{r}(k)$ is an $\mathrm{m}$-dimensional set value vector.

Introduce the following Diophantine equations:

$$
\boldsymbol{I}=\boldsymbol{E}_{j} \Delta \boldsymbol{A}+z^{-j} \boldsymbol{F}_{j} \quad j=1, \cdots, N,
$$

Where,

$$
\boldsymbol{E}_{j} \boldsymbol{B}=\boldsymbol{G}_{j}+z^{-j} \boldsymbol{H}_{j} \quad j=1, \cdots, N,
$$

$$
\begin{gathered}
\boldsymbol{E}_{j}=\boldsymbol{E}^{(0)}+\boldsymbol{E}^{(1)} z^{-1}+\cdots+\boldsymbol{E}^{(j-1)} z^{-(j-1)}, \\
\boldsymbol{F}_{j}=\boldsymbol{F}^{(0)}+\boldsymbol{F}^{(1)} z^{-1}+\cdots+\boldsymbol{F}^{\left(n_{a}\right)} z^{-n_{a},} \\
\boldsymbol{G}_{j}=\boldsymbol{G}^{(0)}+\boldsymbol{G}^{(1)} z^{-1}+\cdots+\boldsymbol{G}^{(j-1)} z^{-(j-1)}, \\
\boldsymbol{H}_{j}=\boldsymbol{H}^{(0)}+\boldsymbol{H}^{(1)} z^{-1}+\cdots+\boldsymbol{H}^{\left(n_{b}-1\right)} z^{-\left(n_{b}-1\right)},
\end{gathered}
$$

And $E^{(i)}, F^{(i)}$ are m-order square matrixes, $\boldsymbol{G}^{(i)}, \boldsymbol{H}^{(i)}$ are $\mathrm{p} \times \mathrm{m}$ dimension matrixes.

Definition:

$$
\begin{gathered}
\widehat{\boldsymbol{Y}}(k)=\left(\begin{array}{c}
\widehat{\boldsymbol{y}}(k+1 \mid k) \\
\vdots \\
\hat{\boldsymbol{y}}(k+j \mid k)
\end{array}\right)_{m \times N}, \\
\Delta \boldsymbol{U}(k)=\left(\begin{array}{c}
\Delta \boldsymbol{u}(k) \\
\vdots \\
\Delta \boldsymbol{u}\left(k+N_{u}-1\right)
\end{array}\right)_{p \times N_{u}}
\end{gathered}
$$

Resolving the Diophantine equations, and then the predictive equations can be obtained as fellow:

$$
\begin{gathered}
\widehat{\boldsymbol{Y}}(k)=\boldsymbol{G} \Delta \boldsymbol{U}(k)+\boldsymbol{Y}_{0}(k), \\
\text { Where } \boldsymbol{G}=\left[\begin{array}{cccc}
\boldsymbol{G}_{0}(k) & \boldsymbol{F}_{j}\left(z^{-1}\right) \boldsymbol{y}(k)+\boldsymbol{H}_{j}\left(z^{-1}\right) \Delta \boldsymbol{U}(k-1), \\
\boldsymbol{G}^{(1)} & \boldsymbol{G}^{(0)} & \cdots & \\
\vdots & \vdots & \ddots & \\
\boldsymbol{G}^{\left(N_{u}-1\right)} & \boldsymbol{G}^{\left(N_{u}-2\right)} & \cdots & \boldsymbol{G}^{(0)} \\
\vdots & \vdots & \ddots & \vdots \\
\boldsymbol{G}^{(N-1)} & \boldsymbol{G}^{(N-2)} & \cdots & \boldsymbol{G}^{\left(N-N_{u}\right)}
\end{array}\right]
\end{gathered}
$$

Let the increment of future control variables be : $\Delta \boldsymbol{u}(k)=$ $\boldsymbol{\delta}, \Delta \boldsymbol{u}(k+i)=\beta \Delta \boldsymbol{u}(k+i-1)=\beta^{i} \boldsymbol{\delta}, 1 \leq i \leq N_{u}$

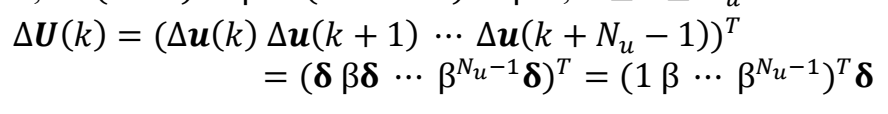




$$
\begin{aligned}
& \boldsymbol{G} \Delta \boldsymbol{U}(k)=\left[\begin{array}{cccc}
\boldsymbol{G}^{(0)} & & \cdots & \\
\boldsymbol{G}^{(1)} & \boldsymbol{G}^{(0)} & \cdots & \\
\vdots & \vdots & \ddots & \\
\boldsymbol{G}^{\left(N_{u}-1\right)} & \boldsymbol{G}^{\left(N_{u}-2\right)} & \cdots & \boldsymbol{G}^{(0)} \\
\vdots & \vdots & \ddots & \vdots \\
\boldsymbol{G}^{(N-1)} & \boldsymbol{G}^{(N-2)} & \cdots & \boldsymbol{G}^{\left(N-N_{u}\right)}
\end{array}\right]\left[\begin{array}{c}
1 \\
\beta \\
\vdots \\
\beta^{N_{u}-1}
\end{array}\right] \boldsymbol{\delta} \\
& =\left[\begin{array}{c}
\boldsymbol{G}^{(0)} \\
\boldsymbol{G}^{(1)}+\beta \boldsymbol{G}^{(0)} \\
\vdots \\
\boldsymbol{G}^{\left(N_{u}-1\right)}+\beta \boldsymbol{G}^{\left(N_{u}-2\right)}+\cdots+\beta^{N_{u}-1} \boldsymbol{G}^{(0)} \\
\vdots \\
\boldsymbol{G}^{(N-1)}+\beta \boldsymbol{G}^{(N-2)}+\cdots+\beta^{N-N_{u}} \boldsymbol{G}^{(0)}
\end{array}\right] \boldsymbol{\delta}=\widetilde{\boldsymbol{G}} \boldsymbol{\delta}
\end{aligned}
$$

Therefore, the predictive equations can be written as fellow:

$$
\begin{gathered}
\widehat{\boldsymbol{Y}}(k)=\widetilde{\boldsymbol{G}} \boldsymbol{\delta}+\boldsymbol{Y}_{0}(k), \\
\min _{\boldsymbol{\delta}} \boldsymbol{J}=\left(\widetilde{\boldsymbol{G}} \boldsymbol{\delta}+\boldsymbol{Y}_{0}(k)-\boldsymbol{Y}_{\boldsymbol{d}}\right)^{T}\left(\widetilde{\boldsymbol{G}} \boldsymbol{\delta}+\boldsymbol{Y}_{0}(k)-\boldsymbol{Y}_{\boldsymbol{d}}\right)+ \\
\boldsymbol{\Lambda}\left(1+\beta^{2}+\cdots+\beta^{2\left(N_{u}-1\right)}\right) \boldsymbol{\delta}^{2}
\end{gathered}
$$

Minimize the objective function $\frac{\partial J}{\partial \delta}=0$, and then obtain the control law as:

$$
\boldsymbol{\delta}=\frac{\widetilde{\boldsymbol{G}}^{\boldsymbol{T}}\left(\boldsymbol{Y}_{\boldsymbol{d}}-\boldsymbol{Y}_{0}\right)}{\widetilde{\boldsymbol{G}}^{\boldsymbol{T}} \widetilde{\boldsymbol{G}}+\boldsymbol{\Lambda}\left(1+\beta^{2}+\cdots+\beta^{2\left(N_{u}-1\right)}\right) \boldsymbol{\delta}^{2}}
$$

In the control process, only the current control amount $\Delta \boldsymbol{u}(k)=\Delta \boldsymbol{u}(k-1)+\boldsymbol{\delta}$ is implemented

\section{B. Overall control scheme}

Considering that the pulverizing system is a multi-input, multi-output, and non-linear system, the inputs and outputs are strongly coupled, in order to fundamentally realize the decoupling control of the coupled system, a multivariable decoupling control scheme for milling system is designed based on multivariate predictive control algorithm; since the change of coal feed flow affects both the primary air temperature and primary air flow, the coal feed flow is used as feedforward to improve the accuracy of the prediction model. The details are as shown in Fig.2.

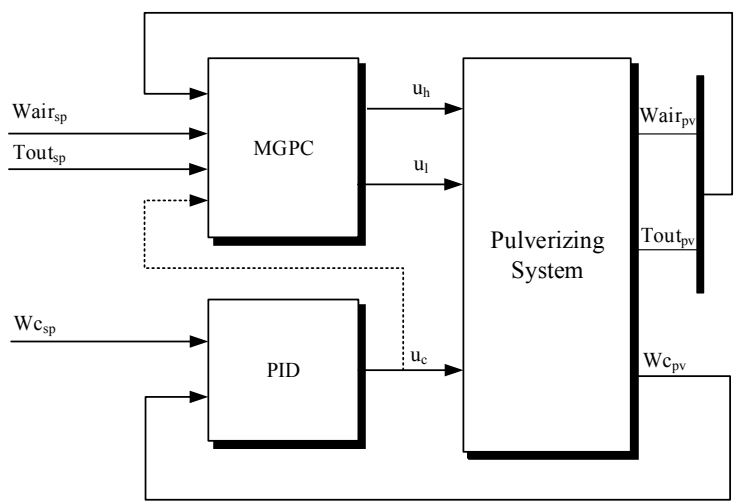

Fig.2 Overall control scheme for the pulverizing system

\section{SIMULATION AND VALIDATION}

In order to verify the effectiveness and accuracy of the control scheme, a simulation experiment was conducted on the mill outlet temperature, primary air flow, and coal powder flow at the outlet of the mill respectively, and a $1 \%$ white noise was added to the coal supply to reproduce the internal coal disturbance. The specific verification process is as follows:

(1) At 500 seconds, the set value of the pulverized coal flow rate at the mill outlet was increased from $9.67 \mathrm{~kg} / \mathrm{s}$ to 11.36 $\mathrm{kg} / \mathrm{s}$, while keeping the other set values constant. As can be seen from Figure 6, the opening of the cold air valve is reduced, and the opening of the hot air valve is increased, this is due to the increase in the amount of coal feed flow requires more energy to dry the raw coal (Figs.3); the increased coal feed flow causes the action of cold and hot air valve, thereby resulting in a temporary deviation of primary air flow and mill outlet temperatures (Figs.4); and it can be seen from Fig. 5 that since the set value of mill outlet temperature is constant, the pulverized coal moisture quickly recovers after a temporary deviation.

(2) At 1500 seconds, the set value of mill outlet temperature was increased from $71.98^{\circ} \mathrm{C}$ to $75.98^{\circ} \mathrm{C}$, while keeping the other set values constant. as can be seen from Figure 3-4, the opening of the cold air valve is reduced, and the opening of the hot air valve is increased, the mill outlet temperature rises and stabilizes to its set value; as the temperature of the mill outlet rises, the pulverized coal is sufficiently dried, resulting in a decrease in pulverized coal moisture and stabilizing to a new steady state value (Fig. 5).

(3) At 2500 seconds, the set value of primary air flow was increased from $24.6 \mathrm{~kg} / \mathrm{s}$ to $28.91 \mathrm{~kg} / \mathrm{s}$, while keeping the other set values constant. As can be seen from Figure 3-4, the hot and cold air flaps are opened at the same time, and the primary air flow rate increases and stabilizes to its new set value.
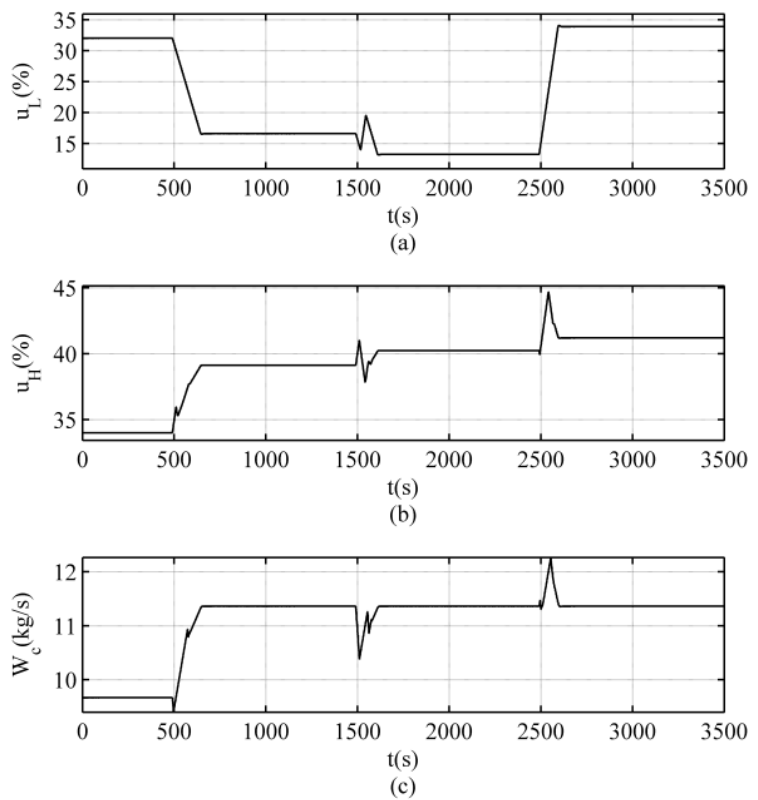

Fig.3 Curve for control variables 


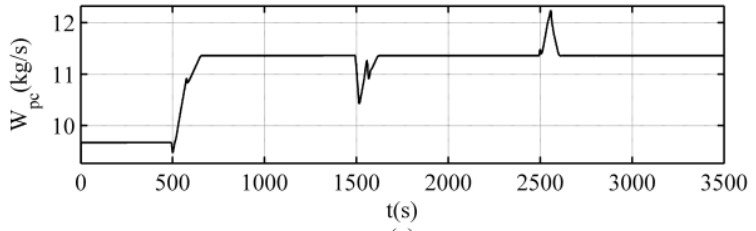

(a)

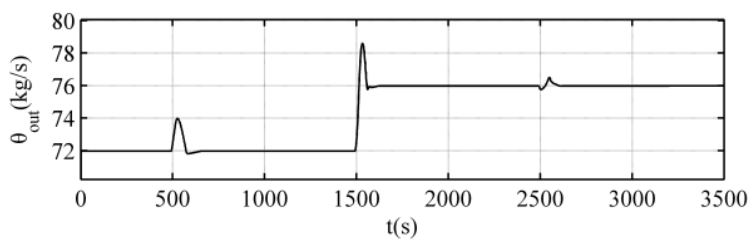

(b)

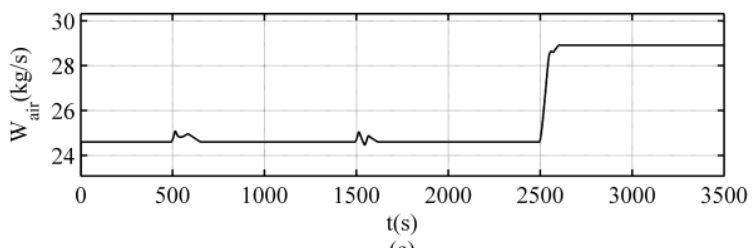

Fig.4 Curve for controlled variables

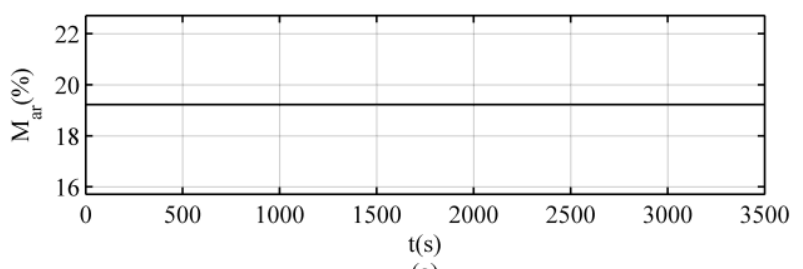

(a)

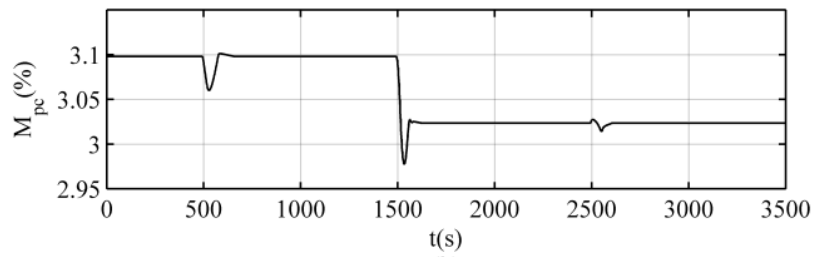

(b)

Fig.5 Moisture of Raw coal and coal powder

\section{CONCLUSION}

In this paper, a control scheme for the pulverizing system based on stair-like multivariable generalized predictive control algorithm is designed. This scheme focuses on the problem of predictive control algorithm in practical application, the pulverized coal at the outlet of coal mill is proposed as a new control target of the pulverizing system's output. Simulation results showed that the scheme can realize decoupling control of the pulverizing system, avoid the problem of matrix inversion, reduce the amount of calculation, and has certain engineering application value, which is of great significance for realizing the clean and efficient utilization of coal in thermal power plants.

\section{REFERENCES}

[1] Bugge J, Kjær S, Blum R. High-efficiency coal-fired power plants development and perspectives[J]. Energy, 2006, 31(10): 1437-1445.

[2] Xu C, Yuan Y. Analysis of present operating situation of large size coalfired utility boilers[J]. Electric Power, 2003, 1: 000.

[3] Sun L, Sun J, Miao Y, et al. Application Research of PID-GPC Algorithm in the Ball Mill System[J]. Open Automation \& Control Systems Journal, 2015, 7(1):157-166.

[4] Fei M, Zhang J. Robust Fuzzy Tracking Control Simulation of Mediumspeed Pulverizer[M]. Systems Modeling and Simulation. Springer Japan, 2007: 78-82.

[5] Zeng D, Hu Y, Gao S, et al. Modelling and control of pulverizing system considering coal moisture[J]. Energy, 2015, 80: 55-63.

[6] Gao Y, Zeng D, Liu J, et al. Optimization control of a pulverizing system on the basis of the estimation of the outlet coal powder flow of a coal mill[J]. Control Engineering Practice, 2017, 63:69-80.

[7] Gao Y, Zeng D, Liu J. Modeling of a medium speed coal mill[J]. Powder Technology, 2017.

[8] Xiaotian L I, Xin W, Wang Z, et al. A stair-like generalized predictive control algorithm based on multiple models switching[J]. Ciesc Journal, 2012, 63(1):193-197.

[9] Wu G, Peng L X, Sun D M. Application of stair-like generalized predictive control to industrial boiler[C]// IEEE International Symposium on Industrial Electronics. IEEE, 1992:218-221 vol.1.

[10] Qiu X, Xue M, Sun D, et al. The stair-like generalized predictive control for main-steam pressure of boiler in steam-power plant[C]// Intelligent Control and Automation, 2000. Proceedings of the, World Congress on. IEEE Xplore, 2000:3165-3167 vol.5. 